\section{IJ§ER}

ISSN: 2149-5939
International Journal of Social Sciences and Education Research

Online, http://dergipark.gov.tr/ijsser

Volume: 3(1), 2017

\title{
Bağlam temelli öğrenme yaklaşımının öğrencilerin çevreye yönelik tutumlarina etkisi
}

\section{The effects of concept based learning approach towards students' environmental attitudes}

\section{Tohit Güneș ${ }^{1}$}

Received Date: 01 / 09 / 2016

\section{Zeynep Öner ${ }^{2}$}

Accepted Date: 22 / 12 / 2016

$\ddot{\partial} z$

Bu çalışma, 8. sınıffen bilimleri dersi “Canlılar ve Enerji İlişkileri” ünitesinde uygulanan bağlam temelli ögrenme yaklaşımının öğrencilerin çevre tutumları üzerine etkisinin belirlenmesi amacıyla yapılmıştır. Çalışma, Samsun ilindeki bir ortaokulda öğrenim gören 20 deney grubu ve 19 kontrol grubu olmak üzere toplam 39 ögrenci ile yürütülmüstür. Kontrol grubuna mevcut uygulama ile ders anlatılırken deney grubuna ünite kazanımlarl dikkate alınarak hazırlanan bağlam temelli öğretim uygulanmıştır. Deney ve kontrol grubuna çalışma öncesi ve sonrasında 25 sorudan oluşan 5 'li likert tipi çevre tutum ölçeği uygulanmış, ayrıca 9 açık uçlu sorudan oluşan yarı yapılandırllmış nitel veri toplama aracı kullanılmıştır. Tutum ölçeğinden elde edilen veriler SPSS 17.0 paket programı kullanılarak analiz edilmiş, nitel veriler içerik analizi ile değerlendirilmiştir. Tutum ölçeğinden elde edilen veri

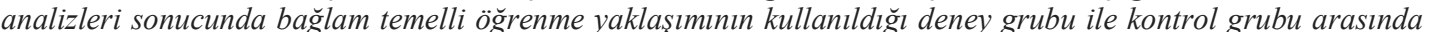
anlamlı farklılık olmadiğı saptanmıştır. Ayrıca açık uçlu sorulardan elde edilen veriler değerlendirildiğinde hem kontrol grubunda hem deney grubunda öğrenme öncesi ve sonrası arasında farklılıklar olduğu ve her iki grupta ögrenme öncesi mevcut kişisel ve duygusal değerlendirmelerin yerine bilimsel değerlendirmeler yapıldı̆̆ saptanmıştır.

Anahtar Sözcükler: Bağlam temelli ögrenme, çevresel tutum

\begin{abstract}
The study is performed to determine the effects of the concept based learning approach which has been carried out at 8th grade science lesson "Living Things and Energy Interactions" unit, towards students' environmental attitudes. The study has been carried out with totally 39 students, being 20 of them are the experimental and 19 of them are the control group attending at a public secondary school in Samsun. The control group has been taught by existing practices and the experimental group has been taught by the concept based learning approach practices formed considering the learning attainments as part of the unit. Environmental attitude scale (five point Likert) consisting 25 questions and qualitative measurement instrument 9 semi-structured open ended questions have been applied to the experimental and control groups before and after the practices. The data acquired from the environmental attitude scale have been analysed using SPSS 17.0 programme, qualitative data have been evaluated by content analyses. As a result, analyses acquired from the environmental attitude scale it has been determined that there is no significant difference between the experimental group which has been applied context based learning approach and control group about environmental attitudes. In addition, when evaluated the data collected by openended questions, it has been determined that there are differences between before and after learning in either the experimental group or the control group and there are changes in each group towards carrying out scientific evaluations instead of personnel and emotional evaluations which has been carried out before learning.
\end{abstract}

Keywords: Concept based learning, environmental attitude

\footnotetext{
${ }^{1}$ Prof. Dr., Ondokuz Mayis University, Faculty of Education, Department of Primary Education, Science Education, Samsun/Turkey tohitg@omu.edu.tr

2 Sorumlu yazar, Ondokuz Mayıs University, Faculty of Education, Department of Primary Education, Science Education, Samsun/Turkey, zeynepce2010@gmail.com
} 
Güneş, T., Öner, Z. (2017). Bağlam temelli öğrenme yaklaşımının öğrencilerin çevreye yönelik tutumlarına etkisi. International Journal of Social Sciences and Education Research, 3(1), 345-355.

\section{Giriş}

Fen bilimleri, yaşamı anlamaya ve kolaylaştırmaya yönelik bir bilim dalı olması nedeniyle bireylerin öğrendiklerini yaşamlarında kullanabilmelerini amaçlar. Fen bilimleri artık yaşam bilimleri olarak ele alınmakta ve elde edilen bilgiler kullanılarak teknoloji geliştirmeyi üretmeye yönelik olarak bilginin kullanılmasını amaçlamaktadır. Bu nedenle fen bilimleri konuları anlatılırken mutlaka günlük yaşamla ilişkilendirilmesi ve öğrencinin yaşam düzeneği içerisindeki herhangi bir durumla ilişkilendirilmesi gerekmektedir. Bu nedenle yaşamın herhangi bir kesitini ele alarak öğretmeyi amaçlayan bağlam temelli öğretim yaklaşımının fen eğitimine uygun olduğu değerlendirilmektedir. Çünkü tüm insanlar kendi yaşamında kullanabileceği bilgileri daha istekli bir şekilde almaya koşullanmış durumdadırlar. Fen eğitiminin temel amaçlarından biri öğrencilerin elde ettikleri bilgileri günlük yaşama ve teknoloji üretimine dönüştürmek için davranış kazanması ve bilinmeyenler konusunda tahminde bulunabilme yeteneğinin geliştirilmesini sağlamaktır. Nitekim Milli Eğitim Bakanlığının fen bilimleri programlarının oluşturulmasında da benzer amaçlar yer almıştır. Bu programa göre bireylerden beklenen, fen ve teknolojinin doğasını özümseyip toplum ve çevre ile olan etkileşimini anlamlandırması ve bu anlamlandırmadan edindiği anlayış ve becerileri kullanarak günümüz sorunlarına çözüm yolu üretmesidir (Milli Eğitim Bakanlığı, 2005a).

Fen bilimlerinin öğrenilmesi sırasında çevre ile etkileşimin sağlanması, yaşamla bağlantının kurulması büyük önem taşımaktadır. Özellikle öğrenilecek konu "çevre ve bileşenleri" ise bireylerin o çevre ile etkileşiminin sağlaması ve aktarılmak istenen bilgilerin yaşam düzeneği içerisine sokulması hem öğrenmeyi kolaylaştıracak hem de öğrenilen bilginin yaşam içerisinde kullanılmasını sağlayacaktır. Birey etkileşim halinde bulunduğu çevresiyle yaşamını sürdürdüğü için bu süreçte yaşadıklarının bir kısmı o bireyin yaşam düzeyindeki bir kesiti düşündügümüzde zaten her koşulda bağlam temelli öğrenmeler gerçekleşiyor demektir. Bu öğrenmeler sonucu bireylerde çevre bilincinin gelişmesi, çevre duyarlılığı, kalıcı davranış değiş̧iklikleri, doğal, tarihi, kültürel, estetik değerleri koruma ve çevre sorunlarının çözümünde görev alma gibi yapılanmalar oluşmaktadır (ÇOB, 2007, s.533). Tung, Huang ve ve Kawala (2012)'ya göre doğaya saygı duymayı öğrenmek, çevreye önem vermek ve onunla birlikte var olmanın nasıl gerçekleştiğini anlamak gerekir ve ki bu yaşam boyu öğrenmenin temel özelliklerinden biridir. Erol ve Gezer (2006)'e göre çevre eğitimi ile insanların ekolojik dengeyi ve bu denge içindeki rollerini kavramaları, gezegenle nasıl uyum içinde yaşayabileceklerine ilişkin görüş geliştirmeleri, etkin ve sorumlu bir katılım için gerekli becerileri kazanmaları da amaçlanmaktadır. Bu bilişsel ve duyuşsal kazanımların kazandırılabilmesi için gerçekleştirilen bağlam temelli öğrenme öğrencilerin zihinlerinde bağlamlar oluşturarak öğrenmenin anlamlı ve kalıcı olmasını sağlar.

Bağlam temelli öğrenme yaşam düzeneğinden kesitler alınması şeklinde gerçekleştirildiği için öğrenci, öğretmen ve okulun bulunduğu sosyal ve kültürel çevreyi kapsamaktadır (Demircioğlu, 2008). Bireylerin yaşadığı toplumdaki sosyal ilişkileri, yaşamak için kullanmış olduğu araçlar ve yaşarken edindiği deneyimler birbirleri ile bağlantılı olup yaşama dayalı bağlamlar oluşturmaktadır (Lave, 1996). Bu nedenle bağlam temelli öğrenme yaşamdan kesitler ele aldığı için öğrenilen bilgilerin yaşama uygulanması için de önemlidir. Yaşam bilimleri olarak ele alınan fen bilimleri dersinde bilginin günlük yaşamla ilişkilendirilmesi amaç edilmiş olduğuna göre ortaokul öğrencilerinin fen bilimleri derslerinde yer alan ünitelerle ilgili ilişkilendirme yapıp yapmadıkları büyük önem taşımaktadır. Bu nedenle aynı grup öğrencilerin benzer yaşam düzeneğine sahip olduk- 
Güneş, T., Öner, Z. (2017). The effects of concept based learning approach towards students' environmental attitudes. International Journal of Social Sciences and Education Research, 3(1), 345-355.

ları çevre içerisinde "Canlılar ve enerji ilişkileri ünitesi”" kapsamında bağlam oluşturup oluşturmadıklarını saptamak amacıyla bu çalışma planlanmış ve ortaokul 7. sınıf öğrencilerinin yapılan bağlam temelli öğretimin, öğrencilerin çevreye karşı tutumlarına etkisini ortaya koymak amacıyla yapılmıştır.

\section{Yöntem}

Çalışma, uygulanan bağlam temelli çevre eğitimin 7. sınıf ortaokul öğrencilerinin çevreye karşı tutumlarına olan etkisini araştırmak amacıyla Samsun ili Bafra ilçesindeki bir ortaokulda öğrenim gören 20 deney, 19 kontrol grubu olmak üzere toplam 39 öğrenci ile yürütülmüştür. Çalışma ünite kazanımlarının tamamlanma süresi olarak 3 hafta süresince yürütülmüştür. Her iki gruba Atasoy (2005) tarafından geliştirilen "İlköğretim Öğrencileri Çevre Tutum Ölçeği (İÇÖ)" öntest ve sontest olarak uygulanmıştır. Deney ve kontrol gruplarına ünitenin öğretimi yapılmadan önce ve öğretim yapıldıktan sonra olmak üzere 9 yarı yapılandırılmış sorudan oluşan çevre tutum anketi uygulanmıştır. Uzman görüşü alınarak hazırlanan ve çevre sorunlarını anlatan bağlam temelli hikayeler deney grubunda uygulama süresince derslerde kullanılmıştır. Kontrol grubuna ise mevcut uygulama ile ders anlatılmıştır. İlköğretim Öğrencileri Çevre Tutum Ölçeği (İÇTÖ), SPSS 17 programı kullanılarak Mann Whitney U testi ile analiz edilmiştir. Çalışma öncesi ve çalışma sonrasında uygulanan tutum anketinden elde edilen veriler içerik analizi yapılarak değerlendirilmiştir.

\section{Bulgular}

\section{1. Çevre tutum ölçeği bulguları}

Deney ve kontrol gruplarına öntest-sontest olarak uygulanan "İlköğretim Öğrencileri Çevre Tutum Ölçeği (İÇTÖ)" için yapılan öntest sonuçlarına göre deney ve kontrol gruplarının Mann Whitney U testi ile analiz sonucunda $\mathrm{p}$ değeri 0.474 olarak bulunmuş ve bu p değeri 0.05 'e göre değerlendirildiğinde deney ve kontrol grupları arasında anlamlı bir ilişki olmadığı saptanmıştır. Sontest sonuçlarına göre deney ve kontrol gruplarının analizi sonucu p değeri 0.492 olarak bulunmuş ve bu p değeri 0.05 'e göre değerlendirildiğinde deney ve kontrol grupları arasında anlamlı bir ilişki olmadığı saptanmıştır. Sonuçlar tablo 1 ve tablo 2'de gösterilmiştir. Bu sonuç dikkate alındığı zaman öntest ve sontest sonuçları arasında her ikisi açısından da bir farklılık olmadığı görülmektedir.

Tablo 1. Gruplararası öntest karşılaştırma sonuçları

\begin{tabular}{|c|l|c|c|c|c|c|}
\hline \multicolumn{6}{|c|}{ Öntest sonuçlarma göre deney ve kontrol gruplarnnı Mann Whitney U testi } \\
\hline \multirow{2}{*}{} & Gruplar & $\mathrm{N}$ & $\begin{array}{c}\text { Stra } \\
\text { ortalamalar1 }\end{array}$ & Stra toplamlar1 & U & $\underline{\underline{p}}$ \\
\hline \multirow{2}{*}{ Ön test } & Deney grup & 20 & 18,28 & 365,50 & 155,50 & 0,474 \\
\cline { 2 - 8 } & Kontrol grup & 18 & 20,86 & 375,50 & & \\
\hline
\end{tabular}


Güneş, T., Öner, Z. (2017). Bağlam temelli öğrenme yaklaşımının öğrencilerin çevreye yönelik tutumlarına etkisi. International Journal of Social Sciences and Education Research, 3(1), 345-355.

Tablo 2. Gruplararası sontest karşılaştırma sonuçları

\begin{tabular}{|c|c|c|c|c|c|c|}
\hline \multicolumn{7}{|c|}{ Sontest sonuçlarına göre deney ve kontrol gruplarının Mann Whitney U testi } \\
\hline & Gruplar & $\mathrm{N}$ & $\begin{array}{c}\text { Sira } \\
\text { ortalamalar1 }\end{array}$ & Sira toplamlari & $\mathrm{U}$ & $\underline{\mathrm{p}}$ \\
\hline \multirow[t]{2}{*}{ Son test } & Deney grup & 20 & 20,68 & 413,50 & 156,50 & 0,492 \\
\hline & Kontrol grup & 18 & 18,19 & 327,50 & & \\
\hline
\end{tabular}

\subsection{Açı uçlu sorulardan elde edilen bulgular}

Yarı yapılandırılmış 9 açık uçlu sorudan oluşan çevre tutum anketine verilen öğrenci cevapları analiz edilerek kodlanmış ve kategoriler oluşturulmuştur. Aşağıda anket soruları listelenmiş, öğrenci cevapları ise kategoriler bazında tablolaştırılarak gösterilmiştir.

1) Çevre kirliliği sizi rahatsız ediyor mu?

2) Canlıların tümü korunmalı mıdır? Nedenini açıklayınız.

3) Günlük yaşantımızda çevreyi istemeden de olsa kirlettiğiniz zaman neler hissettiğinizi açıklayını.

4) Bazı canlıların nesillerinin tükenmesinde insanların etkisinin ne olduğunu açıklayınız.

5) Çevreyi ve canlıları korunmak için neler yapılabilir?

6) Çevreyi ve canlıları korumak için bir şey yapıyor musunuz?

7) Çevre kirliliğinden tüm canlılar zarar görür mü, açıklayınız.

8) Canlıların doğal yaşam ortamlarına insanların müdahale etmesi ile ilgili düşüncelerinizi yazinız.

9) Çevrenizde bir çevre sorunu olduğunu anlayabiliyor musunuz?

Tablo 3. Çevre kirliliğinden rahatsızlık duyma ve nedenleri

\begin{tabular}{|l|c|c|c|c|}
\hline \multirow{2}{*}{} & \multicolumn{4}{|c|}{ Öğrenci Sayıs1 } \\
\cline { 2 - 5 } & \multicolumn{2}{|c|}{ DENEY GRUBU } & \multicolumn{2}{c|}{ KONTROL GRUBU } \\
\cline { 2 - 5 } & $\begin{array}{c}\text { Uygulama } \\
\text { öncesi }\end{array}$ & $\begin{array}{c}\text { Uygulama } \\
\text { sonrası }\end{array}$ & $\begin{array}{c}\text { Uygulama } \\
\text { öncesi }\end{array}$ & $\begin{array}{c}\text { Uygulama } \\
\text { sonras1 }\end{array}$ \\
\hline $\begin{array}{l}\text { 1.Canlı yaşamı, doğa (ekolojik } \\
\text { denge) ve küresel boyutta rahatsızlık }\end{array}$ & 13 & 17 & 10 & 15 \\
\hline 2.Estetik hoşnutsuzluk & 8 & 7 & 6 & 3 \\
\hline $\begin{array}{l}\text { 3.Kişisel rahatsızlık (sağlı, utanma, } \\
\text { kızgnlık, kınama, inanç...vb) }\end{array}$ & 4 & 4 & 4 & 5 \\
\hline
\end{tabular}

Tablo 3 incelendiğinde çevre kirliliğinden rahatsızlık duyma konusunda deney ve kontrol grubunda uygulama öncesi ve sonrası karşılaştırıldığında önemli farlılıklar görülmemekle birlikte kontrol grubu öğrencilerin çevre kirliliğinin estetik olarak rahatsızlık verici olduğu düşüncesi uygulama sonrası cevaplarına göre \%50 oranında azalma göstermiştir. Deney grubunda estetik olarak rahatsızlık kategorisinde önemli bir değişiklik olmamıştır. 
Güneş, T., Öner, Z. (2017). The effects of concept based learning approach towards students' environmental attitudes. International Journal of Social Sciences and Education Research, 3(1), 345-355.

Tablo 4. Canlıların tümünün korunması ve nedenleri

\begin{tabular}{|l|c|c|c|c|}
\hline \multirow{2}{*}{} & \multicolumn{4}{|c|}{ Öğrenci Sayıs1 } \\
\cline { 2 - 5 } & \multicolumn{2}{|c|}{ DENEY GRUBU } & \multicolumn{2}{c|}{ KONTROL GRUBU } \\
\cline { 2 - 5 } & $\begin{array}{c}\text { Uygulama } \\
\text { öncesi }\end{array}$ & $\begin{array}{c}\text { Uygulama } \\
\text { sonrası }\end{array}$ & $\begin{array}{c}\text { Uygulama } \\
\text { öncesi }\end{array}$ & $\begin{array}{c}\text { Uygulama } \\
\text { sonras1 }\end{array}$ \\
\hline $\begin{array}{l}\text { 1a.Besin zinciri, ekolojik denge yo- } \\
\text { luyla türlerin korunması }\end{array}$ & 8 & 13 & 5 & 10 \\
\hline 1b. Yaşama hakk1 & 7 & 3 & 10 & 2 \\
\hline $\begin{array}{l}\text { 2.Bazıları korunmalı (çıkar sağla- } \\
\text { diklarımız), tehlike altında olanlar } \\
\text { korunmalı }\end{array}$ & 4 & 2 & 1 & 2 \\
\hline
\end{tabular}

Tablo 4 incelendiğinde en belirgin farklılaşma "Bazıları korunmalı, tehlike altında olanlar korunmalı" kategorisinde görülmüştür. Deney grubunda uygulama sonrası canlıların sadece bazılarının korunması gerektiğine dair düşüncesi olan öğrenci sayıs1 \%50 azalırken kontrol grubunda artmıştır.

Tablo 5. Çevreyi ve canlıları korumaya yönelik yapılabilecekler

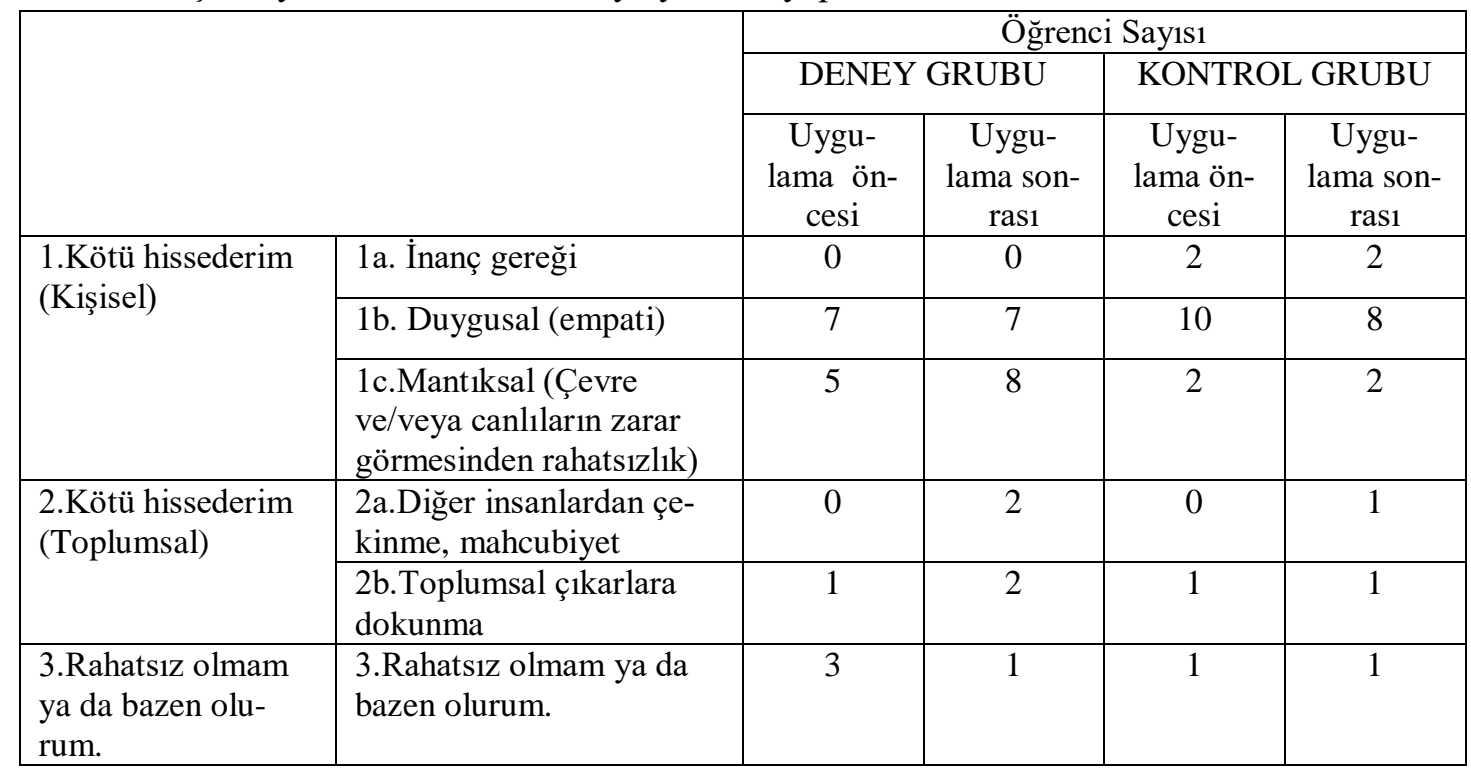

Tablo 5 incelendiğinde çevreyi istemeden de olsa kirlettikleri zaman hissettikleri konusunda "Kötü hissederim." kategorisinde mantıksal düşünme durumu deney grubunda artış gösterirken (5'ten 8 öğrenciye çıkmış.) kontrol grubunda herhangi bir değişiklik olmamıştır (uygulama öncesi ve sonrasında 2 öğrenci).

Tablo 6. Canlı nesillerinin tükenmesinde insan etkisi

\begin{tabular}{|l|c|c|c|c|}
\hline \multirow{2}{*}{} & \multicolumn{3}{|c|}{ Öğrenci Sayıs1 } \\
\cline { 2 - 5 } & \multicolumn{2}{|c|}{ DENEY GRUBU } & \multicolumn{2}{c|}{ KONTROL GRUBU } \\
\cline { 2 - 5 } & $\begin{array}{c}\text { Uygulama } \\
\text { öncesi }\end{array}$ & $\begin{array}{c}\text { Uygulama } \\
\text { sonras1 }\end{array}$ & $\begin{array}{c}\text { Uygulama } \\
\text { öncesi }\end{array}$ & $\begin{array}{c}\text { Uygulama } \\
\text { sonras1 }\end{array}$ \\
\hline $\begin{array}{l}\text { 1.Canlılara değer vermeme, insanların on- } \\
\text { lara kendi çkarları doğrultusunda zarar ver- } \\
\text { meleri }\end{array}$ & 11 & 14 & 9 & 7 \\
\hline $\begin{array}{l}\text { 2.Çevre kirliliği, küresel boyut ve/veya do- } \\
\text { ğal kaynakların (su, besin...vb) tüketilmesi }\end{array}$ & 9 & 10 & 7 & 9 \\
\hline
\end{tabular}


Güneş, T., Öner, Z. (2017). Bağlam temelli öğrenme yaklaşımının öğrencilerin çevreye yönelik tutumlarına etkisi. International Journal of Social Sciences and Education Research, 3(1), 345-355.

Tablo 6 incelendiğinde önemli değişim canlıların nesillerinin tükenmesinde insan etkisi konusunda deney grubunda "Canlılara değer vermeme, insanların onlara kendi çıkarları doğrultusunda zarar vermeleri” kategorisinde deney grubundaki cevap sayısında artış ( 11'den 14 öğrenciye ) gözlenirken kontrol grubunda azalma (9'dan 7 öğrenciye) olmasıdır.

Tablo 7. Çevreyi ve canlıları korumaya yönelik yapılabilecekler

\begin{tabular}{|l|c|c|c|c|}
\hline \multirow{2}{*}{} & \multicolumn{4}{|c|}{ Öğrenci Sayı1 } \\
\cline { 2 - 5 } & \multicolumn{2}{|c|}{ DENEY GRUBU } & \multicolumn{2}{c|}{ KONTROL GRUBU } \\
\cline { 2 - 5 } & $\begin{array}{c}\text { Uygulama } \\
\text { oncesi }\end{array}$ & $\begin{array}{c}\text { Uygulama } \\
\text { sonras1 }\end{array}$ & $\begin{array}{c}\text { Uygulama } \\
\text { oncesi }\end{array}$ & $\begin{array}{c}\text { Uygulama } \\
\text { sonras1 }\end{array}$ \\
\hline 1.Eğitimle düzeltme & 5 & 9 & 1 & 3 \\
\hline 2.Cezalarla & 2 & 4 & 1 & 2 \\
\hline 3.Çevre düzenlemeleriyle & 14 & 12 & 15 & 15 \\
\hline
\end{tabular}

Tablo 7 incelendiğinde çevreyi ve canlıları korumaya yönelik yapılabilecekler konusunda deney ve kontrol grubunda uygulama sonrasında "eğitimle düzeltme" sağlanabileceği düşüncesinde artış olmuştur. Bu artış deney grubunda (5’ten 9 öğrenciye), kontrol grubunda (1'den 3 öğrenciye) şeklinde gerçekleşmiştir.

Tablo 8. Çevreyi ve canlıları korumaya yönelik kişisel çabalar

\begin{tabular}{|l|c|c|c|c|}
\hline \multirow{2}{*}{} & \multicolumn{4}{|c|}{ Öğrenci Sayıs1 } \\
\cline { 2 - 5 } & \multicolumn{2}{|c|}{ DENEY GRUBU } & \multicolumn{2}{c|}{ KONTROL GRUBU } \\
\cline { 2 - 5 } & $\begin{array}{c}\text { Uygulama } \\
\text { öncesi }\end{array}$ & $\begin{array}{c}\text { Uygulama } \\
\text { sonrası }\end{array}$ & $\begin{array}{c}\text { Uygulama } \\
\text { öncesi }\end{array}$ & $\begin{array}{c}\text { Uygulama } \\
\text { sonrası }\end{array}$ \\
\hline $\begin{array}{l}\text { 1.Canlılara ve doğaya zarar vermek- } \\
\text { ten kaçınma, canlıları ve doğayı ko- } \\
\text { rumaya yönelik davranışlarda bu- } \\
\text { lunma }\end{array}$ & 10 & 10 & 14 & 13 \\
\hline $\begin{array}{l}\text { 2.İnsanları uyarma, bilgi verme } \\
\text { 3. Yapmiyor, fakat istekli }\end{array}$ & 5 & 10 & 4 & 6 \\
\hline $\begin{array}{l}\text { 4.İstekli değil, kararsız ya da zo- } \\
\text { runlu hissetme }\end{array}$ & 2 & 2 & 0 & 0 \\
\hline
\end{tabular}

Tablo 8 incelendiğinde çevreyi ve canlıları korumaya yönelik kişisel çabalar konusunda "insanları uyarma ve bilgi verme" kategorisinde uygulama sonrasinda deney grubunda 5, kontrol grubunda 2 öğrenci cevap artışı görülmektedir.

Tablo 9. Çevre kirliliğinden tüm canlıların zarar görmesi

\begin{tabular}{|l|c|c|c|c|}
\hline \multirow{2}{*}{} & \multicolumn{3}{|c|}{ Öğrenci Sayı1 } \\
\cline { 2 - 5 } & \multicolumn{2}{|c|}{ DENEY GRUBU } & \multicolumn{2}{c|}{ KONTROL GRUBU } \\
\cline { 2 - 5 } & $\begin{array}{c}\text { Uygulama } \\
\text { öncesi }\end{array}$ & $\begin{array}{c}\text { Uygulama } \\
\text { sonrası }\end{array}$ & $\begin{array}{c}\text { Uygulama } \\
\text { öncesi }\end{array}$ & $\begin{array}{c}\text { Uygulama } \\
\text { sonras1 }\end{array}$ \\
\hline $\begin{array}{l}\text { 1a.Besin zinciri, ekolojik denge se- } \\
\text { bebiyle }\end{array}$ & 4 & 8 & 4 & 7 \\
\hline $\begin{array}{l}\text { 1b.Yaşam alanları kirlendiği ve yok } \\
\text { edildiği için }\end{array}$ & 14 & 8 & 9 & 6 \\
\hline 2.Bazları zarar görür. & 0 & 0 & 2 & 2 \\
\hline
\end{tabular}

Tablo 9 incelendiğinde çevre kirliliğinde tüm canlıların zarar görmesine dair öğrenci görüşlerinde deney ve kontrol grupları arasında uygulama öncesi ve sonrası değişiminde önemli farkl1lıklar görülmemektedir. 
Güneş, T., Öner, Z. (2017). The effects of concept based learning approach towards students' environmental attitudes. International Journal of Social Sciences and Education Research, 3(1), 345-355.

Tablo 10. Doğal yaşam ortamlarına insan müdahalesine yönelik düşünceler

\begin{tabular}{|l|c|c|c|c|}
\hline \multirow{2}{*}{} & \multicolumn{4}{|c|}{ Öğrenci Sayıs1 } \\
\cline { 2 - 5 } & \multicolumn{2}{|c|}{ DENEY GRUBU } & \multicolumn{2}{c|}{ KONTROL GRUBU } \\
\cline { 2 - 5 } & $\begin{array}{c}\text { Uygulama } \\
\text { öncesi }\end{array}$ & $\begin{array}{c}\text { Uygulama } \\
\text { sonras1 }\end{array}$ & $\begin{array}{c}\text { Uygulama } \\
\text { öncesi }\end{array}$ & $\begin{array}{c}\text { Uygulama } \\
\text { sonras1 }\end{array}$ \\
\hline $\begin{array}{l}\text { 1.Doğanın ve canlıların ekolojik } \\
\text { dengesini bozuyorlar. }\end{array}$ & 11 & 13 & 7 & 6 \\
\hline $\begin{array}{l}\text { 2.Insanların çıarları, bencillik, } \\
\text { nankörlük gibi davranışlarla zarar } \\
\text { veriyorlar. }\end{array}$ & 6 & 4 & 8 & 11 \\
\hline
\end{tabular}

Tablo 10 incelendiğinde doğal yaşam ortamlarına insan müdahalesine yönelik düşünceler konusunda deney grubunda "Doğanın ve canlıların ekolojik dengesini bozuyorlar." kategorisinde düşünen öğrenci sayısında uygulama sonrasında artış (11'den 13 öğrenciye), kontrol grubunda ise azalma (7'den 6 öğrenciye) olduğu görülmektedir. "İnsanların çıkarları, bencillik, nankörlük gibi davranışlarla zarar veriyorlar." kategorisinde ise uygulama sonrasında deney grubunda azalma (6'dan 4 öğrenciye), kontrol grubunda ise artış ( 8 'den 11 öğrenciye) görülmektedir.

Tablo 11. Çevre ve çevre sorunlarını algılama

\begin{tabular}{|c|c|c|c|c|}
\hline & \multicolumn{4}{|c|}{ Öğrenci Sayısı } \\
\hline & \multicolumn{2}{|c|}{ DENEY GRUBU } & \multicolumn{2}{|c|}{ KONTROL GRUBU } \\
\hline & $\begin{array}{l}\text { Uygulama } \\
\text { öncesi }\end{array}$ & $\begin{array}{c}\text { Uygulama } \\
\text { sonras1 }\end{array}$ & $\begin{array}{l}\text { Uygulama } \\
\text { öncesi }\end{array}$ & $\begin{array}{c}\text { Uygulama } \\
\text { sonras1 }\end{array}$ \\
\hline $\begin{array}{l}\text { 1a.Çevreye verilen zarardan (Doğal } \\
\text { alanların ve canlı türlerinin yok edi- } \\
\text { lişinden, çevre kirliliğinden) }\end{array}$ & 14 & 12 & 13 & 13 \\
\hline $\begin{array}{l}\text { 1b.Doğanın dengesinin bozulmasın- } \\
\text { dan }\end{array}$ & 1 & 3 & 0 & 3 \\
\hline $\begin{array}{l}\text { 2. Çıkarları ile ilişkisi doğrultu- } \\
\text { sunda (sağlık, hava kirliliği, estetik, } \\
\text { tarım alanları ile ilgili bir durum) }\end{array}$ & 2 & 2 & 2 & 3 \\
\hline
\end{tabular}

Tablo 11 incelendiğinde çevre ve çevre sorunlarını algılama konusunda deney ve kontrol grubunun uygulama öncesi ve sonrası cevap sayısındaki değişiminde önemli farklılıklar görülmemektedir.

\section{Sonuç ve tartışma}

Eğitim bilimleri açısından önemli olan yaparak yaşayarak öğrenme, doğal olarak insanın yaşadığ çevrede de informal öğrenmelerini gerçekleştirmektedir. Ancak formal eğitim sistemimizde bu informal öğrenmelerden kaynaklanan kavram yanılgılarının ya da davranış bozukluklarının düzeltilmesi konusunda yeterli araştırma yapılmamaktadır. Bu konuyla ilgili farkındalık yaratmak ve çevreye karşı duyarlılık oluşturmak için verilen bilginin ve yapılan eğitimin günlük yaşamda kullanılabilirliği dikkate alınmak zorundadır. Farklı algılama düzeyine sahip bireyler toplumsal olarak ortak yaşam alanlarında benzer yaşantılara sahip olurlar. Dolayısıyla eğitim s1rasında bu ortak yaşamdan bağlamlar oluşturulması kolaylaşmış olur. Bu şekilde oluşturulacak günlük yaşamla ilgili bağlamlar yapılacak formal eğitimi ve aktarılacak bilginin aktarılmasını kolaylaştıracaktır. Choi ve Johnnson (2005) yaptıkları çalışmaya göre öğrencilerin günlük yaşamla bağlam kurduğunda bilime karşı ilgilerinin daha fazla olacağı şeklinde görüş bildirmişlerdir. Eğer aktarılan bilgi günlük yaşamla yeterince ilişkilendirilemez ise derse karşı ilgi azalmaktadır (Yaman, Dervişoğlu ve Soran, 2004). İlginin azalması, hem aktarılan bilginin öğrenilmesini 
Güneş, T., Öner, Z. (2017). Bağlam temelli öğrenme yaklaşımının öğrencilerin çevreye yönelik tutumlarına etkisi. International Journal of Social Sciences and Education Research, 3(1), 345-355.

zorlaştırır, hem de bu öğrenmeler sonucu oluşması beklenen tutum ve davranışların kazanılmasını engeller. Literatür incelendiğinde Ramsden (1992); Hoffmann, Häußler, ve Lehrke (1998); Rayner (2005); Poortinga, Steg, ve Vlek (2004), yapmış oldukları çalışmalarda bağlam temelli öğrenme yaklaşımının öğrencilerin ilgilerini arttırdığını tespit etmişlerdir.

$\mathrm{Bu}$ çalışmada toplumsal olarak aynı yaşam ortamını paylaşan, dolayısıyla benzer yaşam kesitleri yani bağlamlar oluşturabilecek öğrencilerin informal öğrenmelerine karşın formal olarak uygulanan öğretim yöntemlerinin yani bağlam temelli öğrenme veya mevcut yöntemle ders anlat1mının öğrencilerin çevreye karşı tutumlarında bir farklılaşmaya neden olup olmayacağ araştırılmıştır. Bu amaçla uygulanan "İlköğretim Öğrencileri Çevre Tutum Ölçeği (İÇTÖ)” sonuçları değerlendirildiğinde deney grubu (bağlam temelli uygulamanın yapıldı̆̆ı) ile kontrol grubu (mevcut yöntemle ders anlatılan) arasında bir farklılık olmadığı saptanmıştır.

Çalışmadaki deney ve kontrol gruplarının açık uçlu sorulara verdikleri cevaplar incelendiğinde bazı konularda benzer düşüncelere sahip oldukları görülürken bazılarında ise bir farklılık oluşmadığı ve daha çok yaşam düzeneklerine uygunluk, kişisel çıkar, ekonomik değerler gibi açılardan benzer algılamalara sahip oldukları görülmektedir. Bu da fen eğitimi açısından bakıldığı zaman fen-teknoloji- toplum-çevre (FTTÇ) değerleri açısından ele alınmalı ve toplum ve çevre şeklinde değerlendirilmelidir.

Kontrol ve deney grubunun bu şekilde ortak ele alınabileceği sorulara baktığımız zaman "Çevre kirliliği sizi rahatsız ediyor mu?", "Çevreyi ve canlıları korunmak için neler yapılabilir?", "Çevre kirliliğinden tüm canlılar zarar görür mü, açıklayınız.", "Çevrenizde bir çevre sorunu olduğunu anlayabiliyor musunuz?" sorularına verilen cevaplarda her iki grupta da uygulama sonrası olumlu yönde farklılaşmaların olduğu, gruplar arasında önemli farklılaşmaların olmadığı tespit edilmiştir. Ayrıca kontrol ve deney grubu arasında "Canlıların tümü korunmalı mıdır? Nedenini açıklayınız.”, “Günlük yaşantınızda çevreyi istemeden de olsa kirlettiğiniz zaman neler hissettiğinizi açıklayınız.”, "Çevreyi ve canlıları korumak için bir şey yapıyor musunuz?”, "Bazı canlıların nesillerinin tükenmesinde insanların etkisinin ne olduğunu düşünüyorsunuz?", "Canl1ların doğal yaşam ortamlarına insanların müdahale etmesi ile ilgili düşüncelerinizi yazınız." sorularında önemli farklılaşmaların olduğu tespit edilmiştir. Kara (2016) da yaptığı çalışmada bağlam temelli öğrenmenin fen bilimleri dersi için öğrencilerin bilgilerini, bilginin günlük hayatta kullanılmasını ve olumlu tutum geliştirme konularında etkili olduğu sonucuna ulaşmıştır. Gilbert (2006), fen dersi içerisinde gerçek yaşam problemlerinin bağlamlarla ele alınmasının önemi üzerinde durmuştur.

Sonuç olarak yapılan araştırmada bağlam temelli öğrenme yaklaşımının özellikle ortak yaşam oluşturması nedeniyle çevre eğitimi içerisinde kullanılmasının yararlı olabileceği kanısındayız. Çünkü elde edilen nitel veriler değerlendirildiğinde öğrencilerin kendi yaşam düzenekleri içerisinde yer alan çevre bileşenleri ile ilgili farkındalıkları ve çevre sorunları ile ilgili veya çevre korumayla ilgili bilgilenmeleri daha çok olmuştur. Ancak bağlam temelli öğrenme yaklaşımının çevre eğitimi ile ilgili kullanılmasında nicel verilerden çok nitel verilerin daha uygun olduğu görülmektedir. Çünkü nicel veri toplama araçlarında yer alan sorular veya uygulanan anketler eğer deneklerin yaşam düzeneği ile ilgili değilse ya algılanamamakta ya dikkate alınmamakta ya da samimi olarak cevaplandırılamamaktadır. Elde ettiğimiz bulgulara bakıldığında da uygulanan İlköğretim Öğrencileri Çevre Tutum Ölçeği (İÇTÖ)'nde deney ve kontrol grubu arasında bir farkl1lı görülmezken öğrencilerin kendilerini ifade edebildikleri ve kendi yaşam düzeneklerinden aktarabilecekleri bilgileri içeren yarı yapılandırılmış açık uçlu sorularda verdikleri cevaplarda 
Güneş, T., Öner, Z. (2017). The effects of concept based learning approach towards students' environmental attitudes. International Journal of Social Sciences and Education Research, 3(1), 345-355.

önemli farkl11ıklar olduğu görülmektedir. Tüm bu değerlendirmelere göre bağlam temelli öğrenme yaklaşımının özellikle genelleştirmelerin yapılabileceği toplumsal yaşamdan ortak kesitler oluşturabilecek konularda uygulanması sırasında nitel veriler elde edilip ona göre değerlendirmenin doğru olacağı kanısındayız. Özellikle çevre eğitimi açısında ele alındığında bu şekilde yapılacak eğitimin çevre sorunlarının küresel boyutta değerlendirilmesi ve bireysel ya da toplumsal değerlendirmelerin dışında bilginin evrensel olarak ele alınabilmesi için farkındalık yarattığını söyleyebiliriz. Bu da hızla artan çevre sorunlarının küresel boyutta ele alınmasını sağlayacak birey sayısının artmasını etkileyecek önemli faktörlerden biri olarak görülmektedir. Bireylerin öğrendiklerinden hareketle kendi yaşam düzeneklerinde gerçekleştirmiş oldukları küçük olumlu adımların küresel çapta etkiye dönüşeceği gerçeği göz önünde bulundurulursa az sayıda olumsuz tutum ve davranışı olan öğrencinin bile olumluya dönüşebilmesi göz ardı edilemeyecek bir durumdur. Eğitim öğretimde gerçekleştirilen etkili uygulamalarla bu durumun sağlanması çevre ve canlıları korumak için yapılan en uzun vadeli ve etkili uygulamalardan biridir. Böylece çalışmamızda ele alınan "canlılar ve enerji ilişkileri” ünitesinin algılanması bütünsel olarak bir sistem olarak değerlendirilebileceği kanısındayı.

\section{Kaynakça}

Acar, B., Yaman, M. (2011). Bağlam Temelli Öğrenmenin Öğrencilerin İlgi ve Bilgi Düzeylerine Etkisi. Hacettepe Üniversitesi Eğitim Fakültesi Dergisi. (H. U. Journal of Education) 40, 01-10

Atasoy, E. (2005). Çevre için eğitim: ilköğretim öğrencilerinin çevresel tutum ve çevre bilgisi üzerine bir çalışma. Yayınlanmış Doktora Tezi. Bursa: Uludağ Üniversitesi Sosyal Bilimler Enstitüsü

Choi, H. J. \& Johnson, S. D. (2005). "The Effect of Context-Based Video Instruction on Learning and Motivation in On-Line Courses". The American Journal of Distance Education, 19(4), 215-227

ÇOB (2007). Türkiye Çevre Durum Raporu. Ankara. Erişim: 05.10.2011, http://www.cedgm.gov.tr/CED/AnaSayfa/webUygulama/turkiyeCevreDurumRaporu.aspx?sflang=tr

Erol, G. H. \& Gezer, K. (2006). Prospective of elementary school teachers' attitudes toward environment and environmental problems, International Journal of Environmental and Science Education, 1(1): 6577

Gilbert, J. K. (2006). On the nature of "context" in chemical education. International of Science Education, 28 (9), 957-976

Heitzmann, A. (2004). Naturwissenschaftsdidaktik in der Lehrerinnen- und Lehrerbildung im Spannungsfeld zwischen Natur- und Sozialwissenschaften. Beiträge zur Lehrerbildung, 22(1), 5-19

Hoffmann, L., Häußler, P. Lehrke, M. (1998). Die IPN-Interseenstudie Physik. Kiel: IPN

Kara, F. (2016). 5. sinıf "maddenin değişimi" ünitesinde kullanılan bağlam temelli öğrenmenin öğrencilerin bilgilerini günlük yaşamla ilişkilendirme düzeyleri, akademik başarlları ve fene yönelik tutumlarına etkisi. Yayınlanmış doktora tezi. Samsun: Ondokuz Mayıs Ünivesitesi Eğitim Bilimleri Enstitüsü

Lave, J. (1996). The practice of learning. In Understanding practice: Perspectiveson activity and context, ed. S. Chaiklin and J. Lave, 3-32. New York: Cambridge University Press

MEB, (2005a). İlkögrretim Fen ve Teknoloji Dersi 4-5. Sinıflar Öğretim Programı, Ankara: Devlet Kitapları Müdürlüğü Basım Evi

Poortinga, W., Steg, L. \& Vlek, C. (2004). Values, environmental concern and environmental behavior. Environment and Behavior, 36(1), 70-93

Ramsden, J. M. (1992). If it's enjoyable, is it science?, School Science Review,73,65-71

Rayner, A. (2005). Reflections on context-based science teaching: a case study of physics for students of physiotherapy. Univerce Science Blended Learning Symposium Proceedings. Poster Presentation 
Güneş, T., Öner, Z. (2017). Bağlam temelli öğrenme yaklaşımının öğrencilerin çevreye yönelik tutumlarına etkisi. International Journal of Social Sciences and Education Research, 3(1), 345-355.

Tung, C.Y., Huang, C. C. \& Kawala, C. (2002). The effects of different environmental education programs on the environmental behavior of seventh-grade students and related factors. Journal of Environmental Healt, 64(7), 24-29

\section{Extended abstract in English}

Since science is a field for understanding and facilitating life, it aims to enable individuals to use what they have learned in their lives. During the process of science learning, it is of great importance to ensure interaction with the environment and establish connection with life. Especially, if the subject to be learned is "the environment and its components", establishing interaction between individuals and that environment and integrating the information to be transferred within the mechanism of life will both facilitate learning and enable individuals to use the information learned within life. Since the individual continues to live within the environment s/he is in interaction with, considering that some of his/her experiences in this process form a section in that individual's life, it means that concept based learning occurs in all circumstances. Since concept based learning deals with sections of life, it is also important for applying what is learned to life. Considering that the aim of science, which is also discussed as life sciences, is to associate information with daily life, it is of great importance whether secondary school students can associate with the units in science lessons.

The study was conducted with a total of 39 students, 20 in experimental group and 19 in control group, studying at a secondary school in Bafra, Samsun to examine the effects of concept based environmental education on the attitudes of 7 th grade secondary school students. The study was conducted for a period of three weeks, which is the period required for completing unit attainments. "Environmental Attitude Scale for Primary Education Students (EASPES)" was applied as pre-test and post-test on both groups. Environmental attitude scale which consisted of 9 semistructured questions was applied on experimental and control groups before and after the unit was taught. Concept based stories on environmental problems, which were prepared by taking the views of experts, were used in the experimental group in lessons during the period of application. The control group was taught with the existing practice. Environmental Attitude Scale for Primary Education Students (EASPES) was analyzed with Mann Whitney U test by using SPSS 17 program. The data obtained from the attitude scale before and after the study were evaluated with content analysis.

According to the results of the analyzes, There were no significant association between experimental and study groups. When this result is taken into consideration, it can be seen that there are no differences between the two groups in terms of pre-test and post-test results. The fact that there were no differences between the experimental group and the control group brings to mind that informal learning, rather than formal learning may be more effective in students or students can answer the questions in the questionnaire according to learning in his/her life mechanism. Indeed, there are differences between students in the attitude scale that consists of semi-structured open ended questions, which allow them to express their thoughts. We believe that the differences in two different data groups can have occurred due to the characteristics of the environments the practice group live in. For example, while the questions of "Environmental Attitude Scale for Primary Education Students (EASPES)", which gave quantitative data, consisted of formal questions prepared by the researcher, the answers of the questionnaire prepared for qualitative data 
Güneş, T., Öner, Z. (2017). The effects of concept based learning approach towards students' environmental attitudes. International Journal of Social Sciences and Education Research, 3(1), 345-355.

allowed for students' expressing their thoughts depending on their perceptions in their life mechanism.

When the answers of the experimental and control groups to the open-ended questions were examined, it can be seen that while they had similar thoughts in some subjects, there were no differences in others and they were found to have similar perceptions in terms of relevance to their life mechanism, personal benefit and economic values. When this is considered in terms of science education, it should be discussed in terms of science-technology-society-environment (STSE) values and should be evaluated in terms of society and the environment.

As a conclusion, we believe that it may be useful to use concept based learning approach within environmental education especially because it creates a common life. When the qualitative data obtained were assessed, students were found to be more aware of the components of the environment within their own life mechanism and they were found to have more information about environmental problems and protecting the environment. 